DOI: $10.20472 / E S .2020 .9 .2 .003$

\title{
ANALYSIS OF SUBSTITUTION CHANGES IN THE PHILLIPS CURVE IN V4 COUNTRIES OVER THE COURSE OF ECONOMIC CYCLES
}

\author{
BOZENA KADERABKOVA, EMILIE JASOVA, ROBERT HOLMAN
}

\begin{abstract}
:
The aim of the article is to determine the nature and intensity of the slope of the Phillips curves (PCs) for the workers vulnerable to unemployment in the individual phases of the economic cycle between 2000 and 2016 in the Visegrad Group (V4). We use linear regressions to substitute the household deflator of unemployment. In order to avoid a reduction in the number of observations and to reduce the validity of the estimates, which is characteristic of the Break model, we modify the one-year model of the categorical variable phase of the cycle. The results obtained are compared with the findings of international authors. Throughout the monitored period, a statistically significant negative slope of the PC was found in all V4 countries, with the highest intensity in the Czech Republic and the lowest in Hungary. The extrapolation of the trend of the current development of the phases of the economic cycle indicates the growth of the statistically confirmed negative slope of the PC in the Czech Republic, its return to Slovakia, its origin in Hungary and the return of positive inclination in Poland.
\end{abstract}

\section{Keywords:}

Phillips curve, unemployment rate by gender, age and education, phase of the economic cycle, countries of $\mathrm{V} 4$

JEL Classification: E24, E32, E37

\section{Authors:}

BOZENA KADERABKOVA, University of Economics in Prague, Fakulty of Economics, Czech Republic, Email: bozena.kaderabkova@vse.cz

EMILIE JASOVA, University of Economics in Prague, Fakulty of Economics, Czech Republic, Email: ekonomka_2@hotmail.com

ROBERT HOLMAN, Economic University in Prague, Czech Republic, Email: robert.homan@seznam.cz

\section{Citation:}

BOZENA KADERABKOVA, EMILIE JASOVA, ROBERT HOLMAN (2020). Analysis of substitution changes in the Phillips curve in V4 countries over the course of economic cycles. International Journal of Economic Sciences, Vol. IX(2), pp. 39-54., 10.20472/ES.2020.9.2.003 


\section{Introduction}

The theoretical research and empirical research in the Phillips curve (PC) since its publication in 1958 (Phillips, 1958) has been variously intense in individual periods. After a certain decline in interest in this issue, interest has been restored in recent decades and many interesting studies have emerged among many such as Reitz and Slopek (2013), Rusticelli (2014), Watson (2014) and Marjanovic, Maksimovic, Stanisic (2015) and Kloudova (2016). These authors show the makers of economic policy space for PC use in real-life decision making. In particular, when assessing structural reforms based on a proposal for measures to improve the efficiency of the labor market, increase the absorption capacity of the labor market and eliminate labor market imbalances. Application of the PC concept also allows to detect the malfunctioning, asymmetries and barriers to further labor market growth.

This article aims to assess the behavior of the PC in the various phases of the economic cycles of the V4 countries. In order to determine the presence / absence of substitution and its intensity, we are going to modify the standard inflationary equation by means of which we can get a comprehensive view of PC development by gender, age and education in selected countries and at various stages of the economic cycle. The results obtained will then be compared with the findings of the latest available foreign and domestic literature. For this purpose, the article's interpretation is divided into the following parts. The first part provides an overview of the support and questioning of the PC concept in international and domestic research. The second part gives an overview of economic policy measures to promote the involvement of the population in the labor market and the reasons for PC development. The third part summarizes the model approaches to estimating the PC. The fourth describes the used data sources and methods of analysis. The fifth presents an overview of the results from the empirical testing of PC slope development in the V4 countries from the point of view of the economic cycle. The last chapter summarizes the conclusions of the analysis.

\section{Support and denial of the PC concept}

Support for the PC concept stems from the findings of Humphrey (1985) that the formulation of substitution between unemployment and inflation indicators over the 240 years before Phillips was dealt with by at least 10 authors, ie the substitution of inflation - unemployment is historically verified. Phillipse's predecessor can be divided into three groups. The first group consists of authors who assume the relationship between price inflation and unemployment. These include Law (in Humphrey, 1985), Hume (1752), Thornton (1802), Attwood (1816), Mill (1833) and Brown (1955). It is common for authors in the second group to present PC concepts based on wage inflation such as Tinbergen (1951, 1959), Klein and Goldberger (1955). The third group consists of authors dealing with statistical analysis of PC (Fisher, 1926) and the first graphical representation of PC (Sultan, in Humphrey, 1985).

Among the sequels of Phillipse are Samuelson and Solow (1960), Friedman (1968), Phelps (1967), Modigliani and Papademos (1975), Tobin (1997), Gordon (1996), McAdam and McMorrow (1999), Akerlof, Dickens and Perry (1996), Ball and Moffitt (2001), Fabiani and Mestre (2001). Mankiw (2000) considers the short-term substitution between inflation and unemployment to remain a basic insight into the economy. The PC concept also includes recent world and domestic research and empirical analyzes of the years 2013 and 2016 that explain the reasons for changes in the substitution behavior at a time of the global financial and economic recession and after. E.g. Gordon (2013), based on US data analysis, rejects critics' claims that the PC is dead.

According to Coibion and Gorodnichenko (2015), replacing the expectations of firms with the expectations of households eliminates the absence of disinflation. The lack of disinflation is 
explained by the rise in structural unemployment in the United States, which has less impact on wages.

Ma (2014) shows US inflation by the end of the third quarter of 2013 to reduce inflation in all recessions and its expansion in expansion. It also points to differences in growth rates or the decline in inflation across economic cycles.

Rusticelli (2014) analyzes the OECD and European Union (EU) data by the end of 2012. According to the author, the reason for PC flatulence is to reduce the inflationary adjustment of economic dynamics due to the impact of rising rates and prolonged unemployment on the growth of nominal wage rigidity. It is also a consequence of the reduction in inflation due to differences in wage setting among workers and migrants, and in the consumer slopes between domestic and immigrants. It is also the result of well-anchored inflation expectations that weaken the relationship between inflation and labor market imbalances. Finally, it is the impact of greater economic integration, which shifts the resources of the inflation process from domestic pressures to global ones.

The strong relationship between output and inflation demonstrates the great importance of demand shocks for the eurozone economic cycle. Baxa, Plašil, and Vasicek (2013) on US and G7 data between 1st quarter 1995 and 2nd quarter of 2013 find that the relationship between economic activity and inflation is relatively robust only in the case of more complex forms of measurement. In the last decade according to Bax, Plašil and Vašíček (2013) on the data of the USA and G7 countries in the period from 1st quarter 1995 to 2nd quarter 2013, however, the economic output - inflation and thus the so-called flattening of the PC - is weakening. Polluting PV can also be caused by structural changes in the economy and in monetary policy. The authors also find that foreign factors play a major role in inflation in the large G7 countries as well.

Reitz and Slopk (2013) argue that the PC influences the thinking of economists and policymakers, even though inflation movements are more complex than this relationship describes. One of the neglected factors is the decline in nominal wage rigidity. The weakening of the relationship between inflation and unemployment causes a flattening of the $\mathrm{PC}$, which reduces its suitability for creating inflation forecasts. The authors also state that significant institutions continue to estimate PC inflation.

\section{Economic policy measures to promote employment growth and reasons for changing PC tendency}

Cohen (1969) notes that the use of federal programs to support labor market integration in the labor market, for example, workplace education requires that concepts such as PC, labor productivity analysis, and employment measurement be corrected. The PC expresses the relationship between the rate of inflation and the rate of unemployment. Growth in demand for labor leads to PC movements, resulting in lower unemployment rates and wage or price inflation over the period. An alternative is the shifting of the curve, with the PC shifting to the left if the same rate of wage/price growth corresponds to a lower unemployment rate or the same rate of unemployment corresponds to a lower rate of wage / price growth. Labor market support programs move the PC to the left, for example, by shortening job-time (growth of market information on the unemployed decreases their rate at the current rate of wage growth), increasing the number of people in deficient occupations, and training long-term unemployed. Three direct effects of work programs can be analyzed: reducing unemployment by employing people in work programs, employing other unemployed people at work. 
Baily et al. (1977) considers the policy of direct job creation and selective wage support as a means of employing workers who suffer from high levels of unemployment. This intervention in PC substitution in the short term means a reduction in the inflation rate resulting from higher employment rates. In the long run, this means a decline in the natural rate of unemployment. The work of the author focused on the demand for workers with flat PCs due to high unemployment, poor bargaining power or rigid wages. Job support or wage subsidies must be limited to workers whose supply and demand are unrelated to inflation. From the macroeconomic point of view, eligibility criteria for subsidies include: low wages, social dependency, previous unemployment, residency in the surplus of workers, youth.

According to Wallich (1978), a measure that would simultaneously reduce unemployment and inflation, there are many versions of Tax-oriented Income Policies (TIP) in the form of tax penalties or tax bonuses.

Katz et al. (1999) analyze an unusual combination of low unemployment and low inflation in the 1990s. If such a development reflects the labor market, it may be the result of structural changes that can permanently reduce the natural rate of unemployment. If development is caused by factors outside the labor market, it may be a temporary shock that will allow for temporary low unemployment and inflation. PC shifting can cause, for example, a favorable price shock (for example, in computer and energy costs, reducing the cost of healthcare for the employer). It is also the result of a stable relationship between price growth and capacity utilization within the business cycle. The authors presented four hypotheses of this favorable development: demographic trends (age and education) that led to a more mature and more stable workforce, an increase in the prison population that reduces the unemployment rate due to non-inclusion in the workforce, more effective labor market adaptation and job search assistance.

\section{Summary of model approaches to estimating long-term PC}

According to McAdam and McMorrow (1999) there is no direct way to measure unobservable variables. For this reason, it is necessary to apply different methods to reflect the international differences in labor market and product systems in each country. These alternative tools are the cause of a large scatter of estimates. PC assay methods can be categorized into three groups (Richardson et al., 2000). Structural methods are concerned with modeling behavior in wage and price settings. The representative of this group of methods is, for example, the oneyear model (or sometimes the Gordon's "Triangle" model), which estimates only one PC value for the whole of the monitored period. The second group estimates the PC using purely statistical techniques, such as the Break model, which divides the monitored period into several time intervals and estimates one PC value for each of them. The third group is a reduced form method. The representative of this group of methods is, for example, the Kalman filter, which also estimates the time-varying PC. Each method has its strengths and weaknesses (eg. Jašová and Kadeřábková, 2012).

The latest world and domestic research and empirical analyzes from 2013 to 2016 suggest the application of alternative models, the extension of existing models, a combination of several estimation methods, the use of different scenarios by model simulations, the implementation of data verification, the creation of new tests and the construction of new indicators. This group includes, for example, Reitz and Slopek (2013) who use the Stochastic model instead of a traditional PC because the cyclical movement of inflation is much more complex than it can capture the classic PC.

Coibion and Gorodnichenko (2015) expand PCs to household inflation expectations, explaining missing disinflation during the global financial and economic recession. 
Andrle, Brūha and Solmaz (2013) propose a new tool for estimating adjusted average inflation, with upper and lower quanta and the real output frequency band being the most appropriate for cycle inflation. Consistency of output and inflation in relation to the frequency of the business cycle is in the range of 0.6 to 0.9 .

Baxa, Plašil, and Vašíček (2013) apply dynamic dynamics modeling (DMA) to confirm the systematic relationship between real activity and inflation. Zhang (2017) transcribes the basic inflation dynamics model as an expanded form of a conventional PC, to which it adds, besides the domestic production gap, also foreign.

Furuoka (2014) seeks to confirm the presence of unemployment hysteresis in 14 regions of the Czech Republic and also in Central and Southern Europe in the period from 1st quarter 1995 to 1st quarter 2013. The empirical analysis is based on SURADF (Seemingly unrelated regression Augmented Dickey-Fuller test) and the FADF (Fourier Augmented Dickey-Fuller test), which the author creates by extending the commonly used univariate unit root test (Augmented Dickey-Fuller test further to the ADF test). Unit root tests confirm the presence of hysteresis in Austria, the Czech Republic, Hungary, Poland, Slovakia and Slovenia. In these countries, the high unemployment rate persists for a long time. In Bulgaria and Romania, the unemployment hysteresis is not proven and the high level of unemployment will therefore return to equilibrium.

\section{Description of used data sources and methods of analysis}

The slope of the PC, its character and its intensity were examined using the total unemployment rate (aged 15-64), by sex, age and educational attainment level (percentages of unemployment by gender, age and education). All sub-combinations of this labor market indicator were taken from Eurostat (Eurostat, 2017). The V4 countries were selected for research on the basis of economic development. This is given by the administrative measures in the transition from a centrally planned to a market economy, similar to the structure of economies and a similar degree of openness, and a consequence of the great susceptibility to continual changes. Unlike previous aggregate data (both macro and meso), we will now focus on analyzing combinations resulting from the breakdown of aggregate indicators of unemployment by gender, age and education.

From Eurostat (Eurostat, 2017), labor market-related indicators were drawn. In particular, employment incentives - Employment incentives and start-up incentives (average annual status) were shown to be statistically significant. Household deflator, consumer price indices, GDP at constant prices, import prices and Brent crude oil prices (in all cases year-on-year changes in\%) were published on the OECD website (Global Economic Outlook, 2017).

In addition to these numerical variables, time series of these categorical variables were also compiled: gender, age, education, V4 countries and cycle phases. The category variable of the cycle, which was to capture cyclical fluctuations in the economic development in the time series, was based on the statistically published development of GDP at constant prices. The whole time period was then divided into five periods in all countries. Specifically, it is the period of the first boom (1st quarter 2001 to 4th quarter of 2008 - except Czech Republic, where it was only until the 3rd quarter of 2008), the first recession (1st quarter to 4th quarter of 2009 - except the Czech Republic where this was already in Q4 2008), the second boom (1st quarter 2010 to 1 st quarter 2012 - except Hungary and Poland, where it was only until Q4 2011), second recession (1st quarter to 4th quarter 2012 respectively in the fourth quarter of 2013 in Hungary and Poland and from the 2nd quarter of 2012 to the third quarter of 2013 respectively in the fourth quarter of 2013 in the Czech Republic and Slovakia) and the third boom (from 1st quarter 2013 - 
Hungary , or from 4th quarter 2013 - Czech Republic, or from 1st quarter 2014 - Slovakia and Poland until the 3rd quarter of 2016).

The time series used have a quarterly frequency and provide information on the period from 1st quarter 2000 to 4 th quarter of 2016 . The exception is represented by employment and start-up incentives which are available only from the 1st quarter of 2004. From the original time series of numerical variables, year-on-year changes in\% (employment support, start-up incentives, GDP at constant prices, import prices and Brent crude oil price) and pb (deflator of household consumption) that better offset the dynamics of the labor market.

All used time series were tested by the ADF test (Eviews, 2013), which confirmed their stationarity. Also, all rows (excluding employment by gender, age, and education, which were published even after seasonal adjustment) were seasonally cleaned using the Cenzus X12 (Eviews, 2013) method. We use linear regression to estimate the slope of the PC, the character and the intensity of substitution of the household consumption deflator. The PC slope for unemployment rates in detail from different angles of view is then extracted by defining the categorical variables in interaction with the unemployment rate by gender, age and education. In this way we can determine the slope of the PC, its nature and intensity, and confirm or displace the substitutability of the household consumption deflator for each V4 country by gender, age, education, and the economic cycle.

A clean $\mathrm{R}^{2}$ is applied to the most suitable model to approximate the analyzed data. The Jarque Berus test (Eviews, 2013) is used to test the residual normality. To test the autocorrelation of residues, Breusch-Godfrey's test is applied (Eviews, 2013). For testing the heteroskedasticity of the residues, the Wald test (Eviews, 2013) is used. To measure the viability of multicollinearity, the Variable Inflation Factor (Eviews, 2013) is used in the analysis. The failure of normal residuality tests due to fluctuations in the development of some segments of the explanatory variable and of the calculated year-on-year changes in the case of large numbers of observations makes it possible to assume the validity of a central limit sentence that states that the tests are asymptotically valid. The reason for the presence of heteroskedasticity in the model is the same as for the abnormality. Thus, the point estimates will not be disturbed and will still be underestimated.

The application part of the article exploits the experience of the latest world and domestic research and empirical analysis with the extension of existing models, with a combination of several methods and the construction of new indicators. Because in the application part of the article we want to map the development of the PC in selected periods without reducing the number of observations and decreasing the validity of the estimations, which is typical of the commonly used Break model, we modify the one-year model of the categorical variable phase of the cycle. It determines how throughout the time period unemployment rates by gender, age, and education are several times in which PC's propensity, character, and intensity change with the phase of the economic cycle. Other category variables include gender, age, education and the V4 countries, with which we gain a comprehensive insight into the development of PCs in individual V4 countries.

The slope of the PC, its character and its intensity are obtained by modifying the Standard Model for Inflation according to Sekhon (1999) for categorical variables. The inflation equation is then estimated using the least squares method. The observed value of the regression coefficient of the unemployment rate by sex, age and education then indicates the character and intensity of the PC inclination. In the text, the negative sign is the estimate of PC slope in accordance with economic theory and empirical analyzes. This result is supported by Gordon (2013). Reducing the negative slope of the PC between phases of the economic cycle is considered to be flattening, which is explained by findings from the latest international and domestic research. In 
the case of a positive sign, we are talking about the failure of the substitution between the consumption deflator and the unemployment rate by gender, age and education. This conclusion does not endorse the proponents of PC usability and supports the move to the NKPC. In the case that the categorical variable interacts with the gender, age and education rate of unemployment is not statistically significant in the model, we are talking about not demonstrating substitution. Based on the experience of recent research, various ways of modifying commonly used methods can be applied to improve PC estimates. The regression coefficients in the range of 0.01 to 0.20 in our analysis indicate a very low slope intensity, with a slight slope ranging from 0.21 to 0.40 , ranging from 0.41 to 0.60 indicate a mean, 0.61 to 0.80 strong slope, in the range of 0.81 to 1.00 locate a very strong slope.

\section{Overview of the results from the empirical testing of the PC slope development in the V4 countries from the point of view of the entire monitored period and the economic cycle}

In order to decide on the existence or failure of the substitution of price inflation measured by the household consumption deflator, the gender, age and education rate in V4 countries will assess the PC's propensity, its nature and intensity within the various phases of the economic cycle. Statistically unproved cases of PC with a negative and positive slope can help us to predict the development of the PC in the near short period. The results are the following regression analysis, which is based on the extension of the Gordon's "Triangle" model described in section 3 of this article about categorical variables Time-lapse unemployment rates by gender, age and education for several periods of time. The economic policy measures are based on their general definition in Part 2. Labor market indicators are viewed in all countries in the structure outlined in Section 4 of this article.

Throughout the monitored period, the negative trend of the PC was statistically confirmed in all V4 countries. The highest intensity was found in the Czech Republic $(-0.35)$, followed by Poland with a slope value of -0.25 , Slovakia -0.18 and finally Hungary, where the slope of the PC was only -0.01 . In the case of the Czech Republic, Poland and Slovakia, the result of the analysis is in line with Gordon's conclusion (2013), which resolutely rejects the widely presented failure of the PC and its mission to the intellectual history of economic history. In Hungary, the estimated negative trend of the PC is in line with the conclusions of Marjanovice, Maksimovice and Stanisica (2015), which estimate the small statistically significant impact of the change in consumer prices on the natural rate of unemployment. However, because it is only the result of the age group 15-24 with lower basic education and because it outweighed part of the combination with a positive slope $(+0.14)$, we evaluate the conclusion as a substitution failure in Hungary. The conclusion does not confirm the legitimacy of Gordon (2013) arguments against critics denying PC usability.

In the case of men, the largest negative trend was recorded in the Czech Republic $(-0.39)$, followed by Poland $(-0.23)$, Slovakia $(-0.21)$ and Hungary $(-0.01)$. The average value of the slope in the Czech Republic and Poland was supported mainly by age groups 25-54 and 55-64 with higher secondary education ( -0.66 and -0.47 and -0.26 and -0.25 respectively). In Slovakia it was above all the age of 55-64 with higher secondary education (-0.35) and in Hungary only the age group 15-24 with lower basic education (-0.01).

For women in the Czech Republic, the PC rate was -0.31 , in Poland -0.27 , in Slovakia -0.16 and in Hungary -0.01 . In the Czech Republic and Slovakia, it was mainly 55-64 years of age with higher secondary education ( -0.43 and -0.26 respectively). In Hungary, it was only 15-24 years of age with lower basic education (-0.01), and in Poland it was mainly 55-64 years of age with lower basic education (-0.26). 
The statistically unacceptable negative slope in the Czech Republic is 0.12 , in Poland 0.09 , Slovakia and Hungary 0.06. For men, the mean value was in the Czech Republic -0.13 , in Poland -0.10, in Slovakia and Hungary -0.06. In the Czech Republic, it was mainly the age group 55-64 with higher secondary education (-0.26), Poland, Hungary and Slovakia aged 15-24 with higher secondary education ( -0.17 , resp. -0.10 and -0.09 respectively). For women in the Czech Republic, the value was -0.11 , in Poland -0.09 , in Slovakia and Hungary -0.06 . In the Czech Republic, Poland, Hungary and Slovakia, the highest age group was 55-64 years old with higher secondary education $(-0.27,-0.14,-0.10$ and -0.08$)$.

The mean value of a statistically significant positive PC slope was 0.14 , in Slovakia 0.10 , in Poland 0.07 and in the Czech Republic 0.06 . For men, the value of +0.13 was in Hungary, +0.09 in Slovakia, +0.07 in Poland and +0.05 in the Czech Republic. In all countries, it was mainly the age group 55-64 with higher secondary education $(+0.30,+0.43,+0.12$ and +0.14$)$. For women, the PC value was in Hungary +0.15 , Slovakia +0.11 , Poland +0.07 , and +0.06 in the Czech Republic. In Hungary, Poland and the Czech Republic, the age group was 55-64 years of age with higher secondary education $(+0.37,+0.14$ and +0.13$)$. In Slovakia, it was mainly the age group 25-54 with higher secondary education (+0.29).

The non-significant positive trend was in the Czech Republic +0.13 , in Hungary +0.05 , in Slovakia +0.04 and in Poland was not at all localized. In the Czech Republic it was +0.16 for men and was only the result of a 25-54 age group with a higher secondary education. In Hungary and Slovakia, the trend for men was +0.05 . In the case of Hungary, this was mainly the result of the 55-64 age group with higher secondary education (+0.06). In Slovakia, it was only the effect of this combination of age and education. For women, the trend in the Czech Republic was +0.10 , Hungary +0.05 and Slovakia +0.03 . In the Czech Republic and Slovakia this was the result of only the 25-54 age group with higher secondary education. In Hungary, it was mainly the age group 55-64 with a higher secondary education (+0.08).

The analysis of $\mathrm{PC}$ development in the economic cycle first revealed a typically negative slope for the first boom (1st quarter 2001 to 4th quarter 2008, in the Czech Republic only Q3 2008). In the Czech Republic, the slope was - 0.31 (low intensity, see Figure 1), Slovakia and Poland 0.20 (very weak intensity). In Poland, the rise in unemployment could have a lesser impact on inflation because the unemployment rate is offset by the rise of NAIRU (Watson, 2014). In Hungary, the slope of $-0,01$ indicates the lowest substitutability of the household deflator of unemployment by gender, age and education at the scale set by us. According to Rusticelli (2014), the reason for the flattening of the PC is the reduction of the inflation adjustment of economic dynamics due to the influence of the rising level and the increasing length of unemployment on the growth of nominal wage rigidity.

Figure 1 The development of the slope of the real PC and the estimated econometric model in the individual phases of the economic cycle 

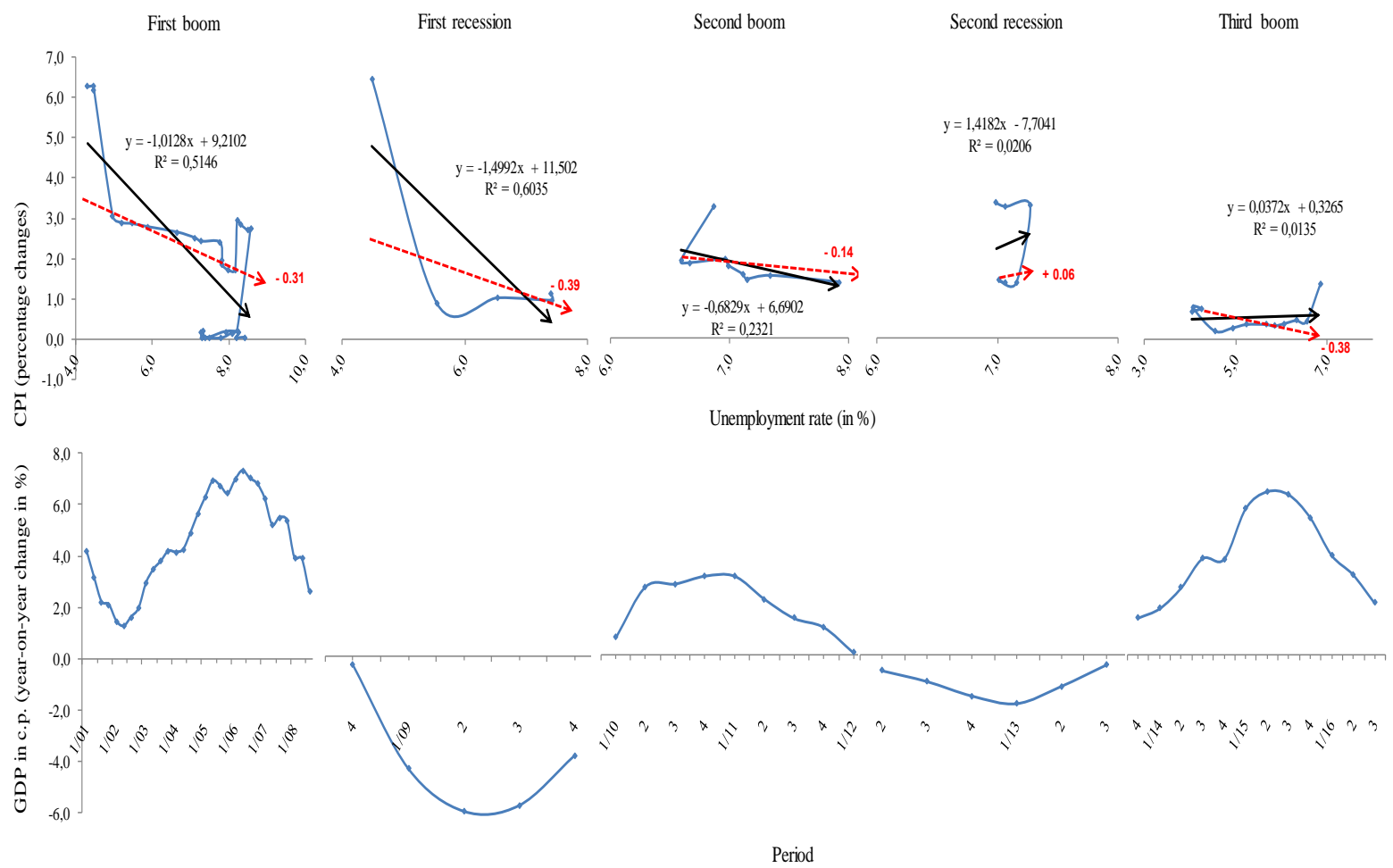

Source: Own calculation based on Eurostat data and OECD

In the case for men in the Czech Republic, the value was -0.35 , in Slovakia -0.20 , in Poland 0.17 and in Hungary -0.01 . In the Czech Republic, moderate substitutability was found at the age of 25-54 and 55-64 with higher secondary education (-0.59 and -0.46). In Slovakia, it was primarily the low intensity of PC ages 55-64 with higher secondary education (-0.27). In the case of Poland, the development was the result of the age group 25-54 with higher secondary education $(-0,18)$ and $55-64$ with both levels of education $(-0,15$ and $-0,17$ respectively). In Hungary, the age group was 15-24 with lower basic education (-0.01).

For women in the Czech Republic, the negative trend was 0.27, Poland 0.24, Slovakia 0.20 and Hungary 0.01. In the Czech Republic, aged 55-64 and aged 25-54 with higher secondary education, we are talking about moderate substitutability of -0.41 and a slight slope of -0.31 . In Poland, it was the influence of the 55-64 age group with both levels of education. In Slovakia, a low intensity was found in the age of 25-54 with a higher secondary education (-0.22), and in Hungary it was the influence of the 15-24 age group with lower basic education.

The negative but statistically insignificant slope of the PC in the Czech Republic amounted to 0.08 , and it was caused by age brackets of 15-24 years and 25-54 years with lower basic education (inclination from -0.05 to -0.10 ) for both men and women. In Poland, the average age of -0.08 (men -0.08 and females -0.09 ) was mainly attributed to men aged 25-54 with lower primary education (PC slope was -0.10 ). In the case of women, the age group was 25-54 with a higher secondary education $(-0.14)$. In Slovakia, the unconfirmed negative slope was on average 0.06 (for men 0.06 and for women 0.07 ) and was caused by age brackets $15-24,25$ 54 and 55-64 with lower basic education (interval from 0.06 to 0.09). In Hungary tests declined by -0.02 average (for men -0.02 and for women -0.01 ).

In the following period - the first recession (in the Czech Republic, 4th quarter 2008 to 4th quarter 2009, in other countries since Q1 2009) in the Czech Republic there was a slight increase in the negative slope of PC against the first boom to 0.39 intensity) and Slovakia at 0.24 (now weak intensity, see Figure 2). PC development in both countries is in line with Gordon's (2013) arguments that disagree with the conclusions of some economists about the inability of economic policy makers to estimate the NAIRU and thereby influence the 
unemployment gap, which is one of the central bank's two core objectives. In Poland, only the negative slope, which was not statistically confirmed $(0.11)$, also indicates a decrease in the intensity of the substitution against the initial period. Coibioni and Gorodnichenko (2015) improve the estimates instead of households' expectations of household expectations and the lack of disinflation, explains the rise in structural unemployment in the US, which has less impact on wages. In Hungary, a positive PC gradient of 0.01 was statistically confirmed. The conclusion confirms the legitimacy of critics pointing to PC failure (Gordon, 2013).

Figure 2 The development of the slope of the real PC and the estimated econometric model in the individual phases of the economic cycle

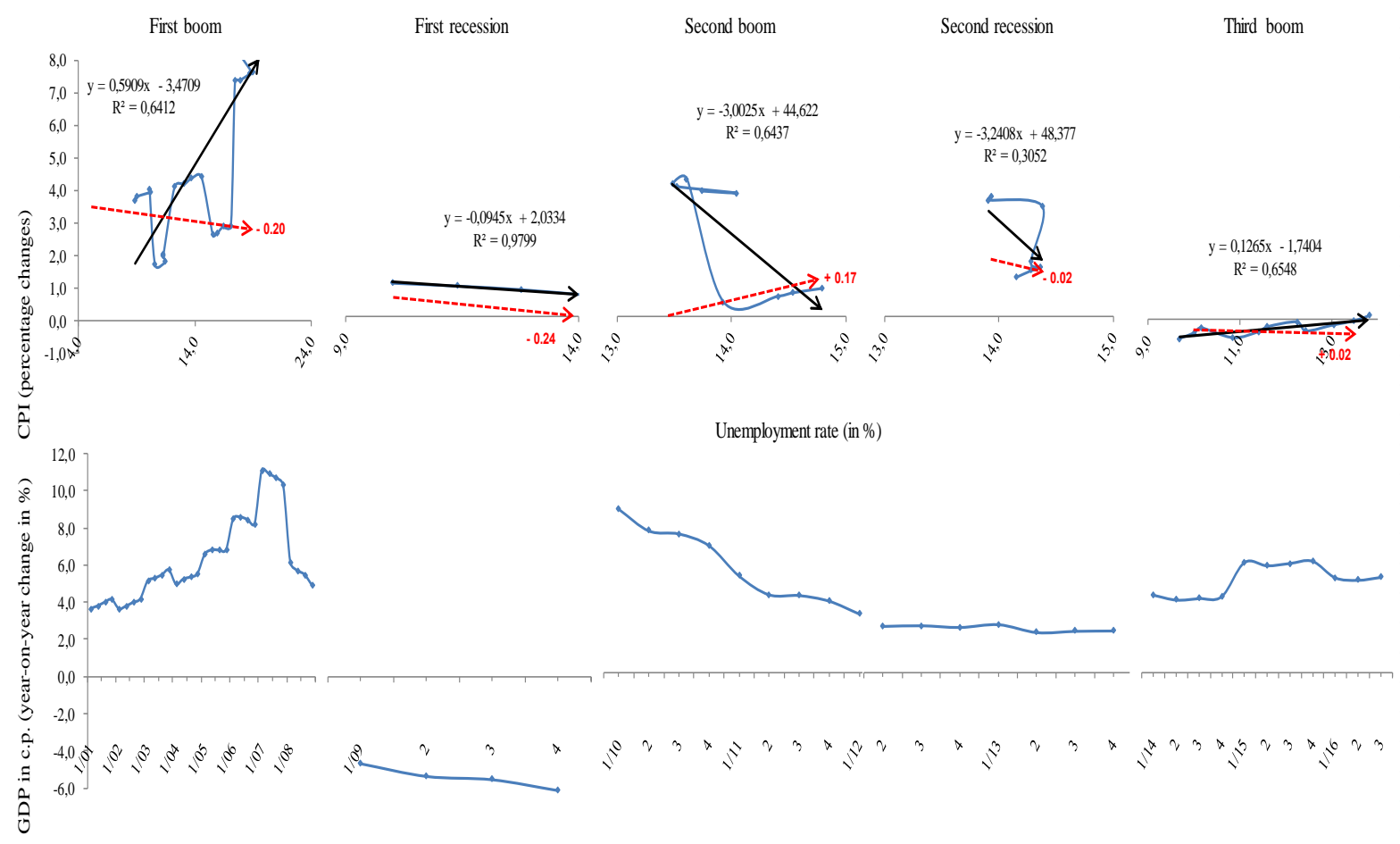

Period

Source: Own calculation based on Eurostat data and OECD

For men in the Czech Republic, the average slope of -0.41 (mean intensity) was the result of the age group 25-54 with a higher secondary education ( -0.90 and a very strong substitution). In Slovakia, the slope increased to -0.43 (middle substitution) due to the 55-64 age group with higher secondary education. In Poland, it was -0.12 due to the age range of 25-54 with a higher secondary education (-0.21). In Hungary, the average positive slope was 0.02 and was the result of a very low replacement rate in the 15-24 age group, 25-54 age group, and 55-64 years old with lower basic education ( 0.01 to 0.02 range).

For women in the Czech Republic, the PC slope increased to -0.36 (now low intensity) due to the age group 15-24 (-0.26) and 25-54 (-0.44) with higher secondary education. In Slovakia, the PC slope decreased against the first period to -0.17 (age 25-54, respectively 55-64 years with higher secondary education -0.23 and -0.26 respectively). In Poland, the mean negative slope was 0.10 and was a consequence of developments in all combinations of age and education. For women in Hungary, the positive slope was 0.01 (a consequence of 15-24 years of age with lower primary and upper secondary education and 25-54 years of lower basic education).

Statistically insignificant negative tendencies in the Czech Republic (average value -0.10) remain age groups 15-24 years and 25-54 years with lower primary education remain $(-0.06$ and -0.12 respectively). In Slovakia, the statistically insignificant negative slope of the PC was found to be 0.08 (in males it was five and in women by three combinations). In Hungary, the 
positive tendency was 0.05 (average age 25-54 and 55-64 with higher secondary education, 55-64 years with lower primary education).

In the next period - the second boom (in Hungary and Poland in the first quarter 2010 to the fourth quarter of 2011, in the Czech Republic and Slovakia in the first quarter of 2012), the theoretically expected substitution between the deflator of household consumption and unemployment by sex, age and education. In the Czech Republic, the positive positive trend was 0.06, Poland 0.07, Hungary 0.12, and Slovakia 0.17. The conclusion confirms the legitimacy of critics pointing to PC failure (Gordon, 2013).

For men in the Czech Republic it was +0.05 , of which in the 55-64 age group with higher secondary education +0.14 . In Poland, it was +0.07 (age group 15-24 with lower education +0.03 and age group 55-64 with upper secondary education +0.12 ). In Hungary, the figure was +0.12 (see Figure 3), due to the age group 55-64 with a higher secondary education $(+0.21)$. In Slovakia, the positive slope of the PC was +0.16 (in the age range 55-64 years with higher education it was even +0.43 ).

Figure 3 The development of the slope of the real PC and the estimated econometric model in the individual phases of the economic cycle

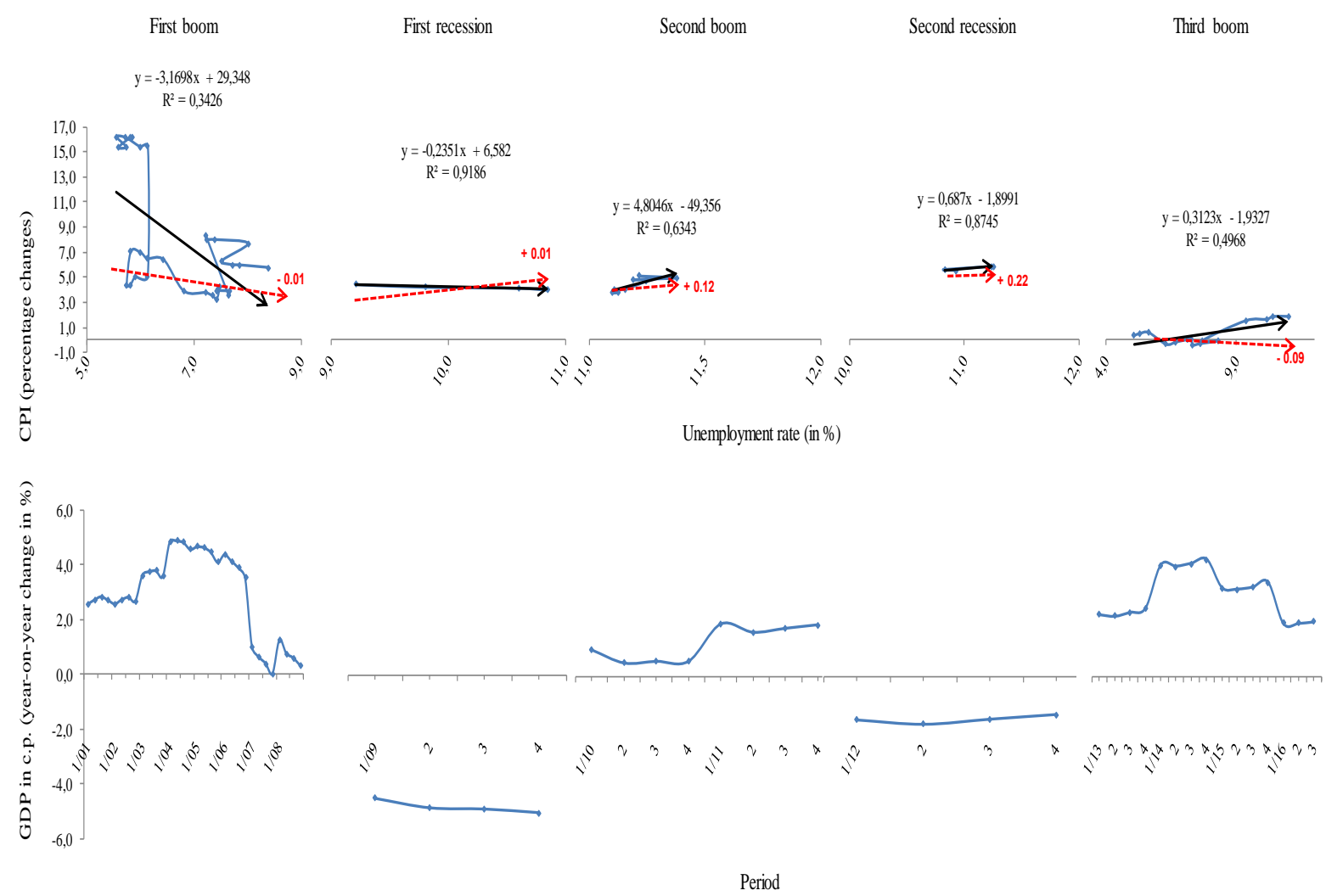

Source: Own calculation based on Eurostat data and OECD

In case for women in the Czech Republic, the positive slope of the PC was 0.06 (the highest rate in the 55-64 age group with higher secondary education 0.13 ). In Poland, the average slope was +0.07 (age group 15-24 with lower primary education +0.02 and 55-64 with upper secondary education +0.14 ). In Hungary, the average slope was +0.13 (age group 55-64 with higher secondary education even +0.27 ). In Slovakia, the positive slope of the PC was 0.18 (age 25-54 and 55-64 years with higher secondary education the PC slope was +0.29 and $+0.38)$.

A positive but statistically unconfirmed PC slope was found only in the Czech Republic (men and women aged 25-54 with higher secondary education +0.16 and +0.10 respectively). 
In the following period - the second recession (the average interval from 1st quarter 2012 to 4th quarter 2013), only the negative slope of the PC was found in Poland, indicating the acceleration of substitutability against the first recession and even against the initial boom $(-0,29)$ see Figure 4. The result of the analysis supports Gordon (2013) in rejecting PC failure and its mission into the intellectual history of economic history. In Slovakia, the very weak negative slope of the PC (0.02) was again statistically confirmed. According to Watson (2014), the reason for the smaller fall in inflation is the change in inflationary persistence. In the Czech Republic, the return of a negative PC slope was localized, which was not statistically confirmed. The value of -0.14 is significantly lower than the PC slope in the initial boom. Coibioni and Gorodnichenko (2015) recommend replacing households' expectations with expectations of households, eliminating the absence of disinflation. In Hungary, the failure of the substitution further strengthened $(+0.22)$, which supports the conclusions of Basist and Nelson (2003), who are joining the NKPC.

Figure 4 The development of the slope of the real PC and the estimated econometric model in the individual phases of the economic cycle

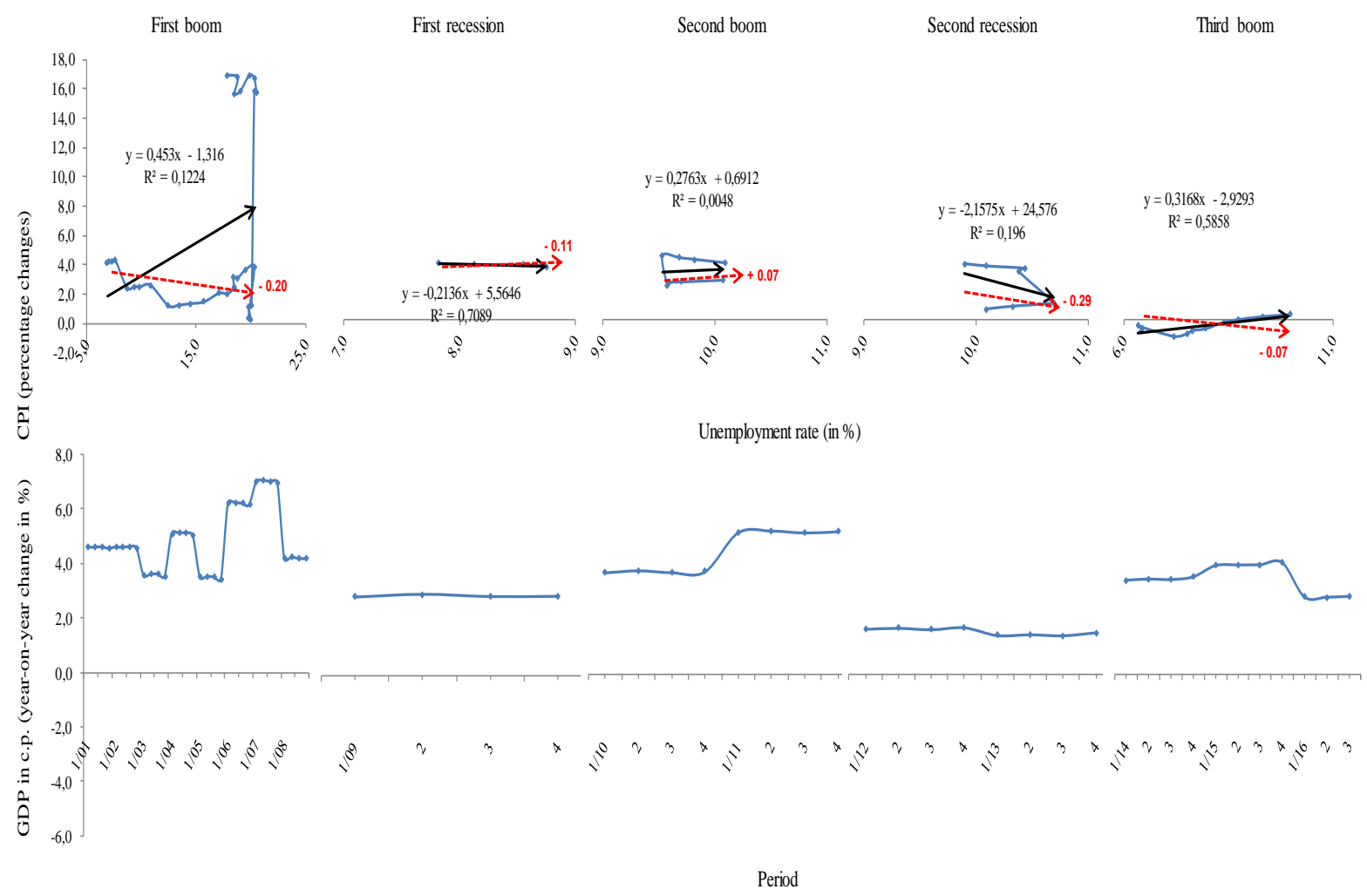

Source: Own calculation based on Eurostat data and OECD

For men, in Poland the value was -0.29 (age group 25-54 and 55-64 with higher secondary education even -0.34 and -0.32 respectively). In Slovakia, the mean value of the slope was 0.02 (only 15-24 years of age with lower basic education). In the Czech Republic it was -0.16 (aged 25-54 and 55-64 with higher secondary education -0.38 and -0.26 respectively). In Hungary, the average positive slope was 0.21 (the age groups 25-54 and 55-64 with higher secondary education +0.36 and +0.38 ) were decisive.

In Poland in case for woman, the average value of the slope was -0.28 (the age group 55-64 years with both levels of education -0.28 and -0.33 ). In Slovakia, the negative slope was only 0.01 thanks to the 15-24 age group with lower basic education. In the Czech Republic, the average negative slope was 0.13 (age group 25-54 and 55-64 years with higher secondary education -0.22 and -0.27 respectively). In Hungary, the average tilt value was even +0.23 (age 55-64 with higher secondary education +0.46 ). 
The average statistically unconfirmed negative slope in Poland was 0.11 of which for men -0.12 and for women -0.10 (mainly age 25-54 with lower primary education -0.15 and -0.13 ). In Slovakia, the mean value was -0.04 , with men -0.03 and women -0.05 (the values of the slope for each combination of age and gender were -0.02 to -0.08 ).

In the last period - the third boom (in Hungary from the 1st quarter of 2013, in the Czech Republic from 4th quarter 2013, in Poland and Slovakia from 1st quarter 2014 to 3rd quarter of 2016), a statistically significant negative slope was localized in the Czech Republic, which was even higher than in the initial analysis period and only slightly lower than in the first recession period (-0.38). PC development within the business cycle has confirmed Gordon's disapproval (2013) with critics claiming the PC is dead due to the coincidence of a small standard core inflation error with high volatility in the unemployment rate and the failure of the PC inflation formula to estimate greater deflation. In Hungary, there was a very weak, statistically insignificant negative slope of 0.09 , which represented an acceleration of substitutability from the initial analysis period. Gordon (2013) to improve model simulations recommends using short-term unemployment instead of long-term unemployment. In Poland, the negative unconfirmed PC slope was only 0.07. Andrle, Brūha and Solmaz (2013) limit the upper and lower quanta and the real output frequency band, which best corresponds to cycle inflation. In Slovakia, only a positive PC weakness (0.02) was confirmed, confirming the legitimacy of critics pointing to PC failure (Gordon, 2013).

For men in the Czech Republic, the average statistically confirmed trend was -0.44 (age group 25-54 with upper secondary education -0.50). In Hungary, the mean negative slope was 0.09 (the highest gradient at the age of 25-54 with a higher secondary education of 0.16 ). In Poland, they were -0.07 (age 25-54 with upper secondary education -0.12). In Slovakia, the positive slope +0.01 was the result of all combinations except for $55-64$ years with lower basic education $(+0.02)$.

In the Czech Republic there was a significant negative slope of 0.32 (age group 55-64 with a higher secondary education of 0.35 ). In Hungary, there was a slope of -0.09 and in Poland by 0.07 (age 55-64 with higher secondary education -0.18 and -0.12 respectively). In Slovakia, the positive slope was 0.02 and again it was almost all combinations.

The value of the statistically unconfirmed negative inclination in the Czech Republic was 0.11 for both men and women. For men, the highest rate was 15-24 years of age with higher secondary education $(-0.15)$ and women aged $15-24$ with lower basic education $(-0.15)$. No positive PC slope was found in Slovakia (0.04). In men, the slope was +0.05 , resulting in the age group 55-64 with a higher secondary education, and for women +0.03 this was a 25-54 age group with a higher secondary education.

\section{Conclusions}

The analysis of the monitored period confirmed in all V4 countries a statistically significant negative, ie a classical, slope of the PC. The largest substitutability of household consumption deflator by unemployment rate by gender, age and level of education was found in the Czech Republic. This was followed by Poland, Slovakia, and finally Hungary, where the PC was the lowest value in our assembled scale for intensity assessment. Analysis of PC development from the economic cycle point of view first revealed in all countries the typical negative slope of the PC at the time of the first boom. In the first recession, the negative slope of the PC in the Czech Republic and Slovakia slightly increased; in Poland, the negative tendency to confirm statistically was confirmed and in Hungary the positive slope of the PC was statistically confirmed. In the second boom, the theoretically expected substitution In the second recession, a negative PC slope was detected in Poland, which accelerated against the previous two phases of the cycle, in Slovakia was again statistically confirmed the very weak negative slope of the 
PC, in the Czech Republic was located the statistically unpredictable negative slope of PC and in Hungary the failure of the substitution further strengthened. On the basis of the previous development, the Czech Republic may expect to increase the negative slope of the PC in the next period, in Slovakia the negative PC slope will probably return to a lower level than in the first boom, in Hungary probably some of the statistically unconfirmed negative PC slopes from the previous phase will move to statistically confirmed negative PC slopes, the most likely in Poland is the return to positive PC slope with very low intensity.

Based on the extrapolation of the trend of the current development of the phases of the economic cycle, it can be assumed in the Czech Republic that in the next period there will be another increase in the value of the statistically confirmed negative slope of the PC. This increase is due to a decrease in the number of cases of a statistically unconfirmed negative slope in the last published period. In Slovakia, it is likely to return the values of the statistically confirmed negative slope of the PC, which however do not reach the values of the first boom and recession but may be higher than in the second resese period. However, the crucial part will be cases with a negative but statistically unconfirmed tendency. In Hungary, some of the statistically unconfirmed negative PC gradients located in the previous phase are likely to move to statistically confirmed negative PC slopes. A slightly larger portion of the combinations and also a higher substitution intensity fall on a part with a negative but statistically unconfirmed slope. Overall, the slope of the PC can be expected at least at the level of the third boom period. In Poland, it is most likely to return to the positive slope of the PC with a very low intensity, which can be partly statistically confirmed and partially unconfirmed.

\section{References}

AKERLOF, G. A.; DICKENS, W. T.; PERRY, G. L. 1996. The Macroeconomics of Low Inflation. Brookings Papers on Economic Aktivity. Brookings Institution. https://doi.org/10.2307/2534646

ANDRLE, M.; BRU゚HA, J.; SOLMAZ, S. 2013. Inflation and Output Comovement in the Euro Area: Love at Second Sight? Working paper Series 7: Česká národní banka.

ATTWOOD, T. 1816. The Remedy; or, Thoughts on the Present Distresses. Second edition, with additions. London.

BAILY, N. M.; TOBIN, J.; HOLT, CH.; WACHTER, M.; TOBIN, J.; JUSTER, T.; FRIEDMAN, B.; PERRY, G.; HALL, R.; OKUN, A.; FELDSTEIN, M.; DUESENBERRY, J.; GORDON, J. R. 1977. Macroeconomic Effects of Selective Public Employment and Wage Subsidies. Brookings Papers on Economic Activity, Vol. 1977, No. 2 (1977), pp. 511-544, Brookings Institution Press. https://doi.org/10.2307/2534409

BALL, L.; MOFFITT, R. 2001. Productivity growth and the Phillips curve [Working paper series]: National Bureau of Economic Research. https://doi.org/10.3386/w8421

BAXA, J.; PLAŠIL, M.; VAŠÍČEK, B. 2013. Inflation and the Steeplechase Between Economic Activity Variables. Working paper Series 15: Česká národní banka.

BROWN, A. J. 1955. The Great Inflation, 1939-1951. London: Oxford University Press.

COHEN, S. M. 1969. The Direct Effects of Federal Manpower Programs in Reducing Unemployment. University of Wisconsin Press: The Journal of Human Resources, Vol. 4, No. 4, pp. 491-507.

COIBION, O.; GORODNICHENKO, Y. 2015. Is the Phillips Curve Alive and Well after All? Inflation Expectations and the Missing Disinflation. American Economic Journal: Macroeconomics 2015, 7(1), 197-232. https://doi.org/10.1257/mac.20130306 
CORNWALL, J. 1981. Do We Need Separate Theories of Inflation and Unemployment Canadian Public Policy / Analyse de Politiques, Vol. 7, Supplement: The Challengeof Inflation and Unemployment / Le defi de l'inflation et du chomage (Apr., 1981), pp.165-178. https://doi.org/10.2307/3550129

EUROSTAT. 2017. http://ec.europa.eu/eurostat/data/database.

EVIEWS. 2013. EViews Version 7.2 Help Topics.

FABIANI, S.; MESTRE, R. 2001. A system approach for measuring the euro area NAIRU. ECB.

FISHER, I. 1926. „A Statistical Relation between Unemployment and Price Changes.” International Labour Review 13. Reprinted as "I Discovered the Phillips Curve." Journal of Political Economy 81 (March/April 1973).

FRIEDMAN, M. 1968. The Role of Monetary policy. The American Economic Review.

FURUOKA, F. 2014. Does Hysteresis Exist in Unemployment? New Findings from Fourteen Regions of the Czech Republic. Finance a úvěr - Czech Journal of Economics and Finance, 64, No. 1, 59-78.

GLOBAL ECONOMIC OUTLOOK. 2017. http://www.oecd.org/economy/outlook/.

GORDON, R. J. 2013. The Phillips Curve is alive and well: Inflation and the NAIRU During the Slow Recovery. National Bureau of Economic Research. Cambridge: Working Paper 19390. https://doi.org/10.3386/w19390

GORDON, R. J. 1996. Problems in the Measurement and Performance of Service-sector Productivity in the United States. National Bureau of Economic Research, March 1996. https://doi.org/10.3386/w5519

HUME, D. 1752. Of Money. Political Discourses by David Hume. Presented by the Worshipful Company of Goldsmiths, 1903.

HUMPHREY, T. M. September/October 1985. The early History of the PHILLIPS CURVE. Economic Review: Federal Reserve Bank of Richmond.

JAŠOVÁ, E.; KADEŘÁBKOVÁ, B. 2012. Comparing NAIRU and Economic Cycle from the Perspective of Labour Market in the Countries of the Visegrad Group. Economic Studies journal, Bulgarian Academy of Scienties, Sofia, Issue 4, volume XXI, ISSN 0205-3292. Bulharsko, 3-23.

KATZ, F.L.; KRUEGER, B.A.; BURTLESS,G.; DICKENS, T. W.1999. The High-Pressure U.S. Labor Market of the 1990s. Brookings Papers on Economic Activity, Vol. 1999, No. 1 (1999), pp. 1-87.

KLEIN, L. R.; GOLDBERGER, A. S. 1955. An Econometric Model of the United States, 1929-1952. Amsterdam: North-Holland Publishing Company.

KLOUDOVÁ, D. 2016. Does using NAIRU in the Production Function Influence Estimation of Potential Output and Output Gap. International Journal of Economic Sciences, Vol. V, No. 2/ 2016. DOI: 10.20472/ES.2016.5.2.001.

MA, J. 2014. The Modern Phillips Curve Revisited. Modern Economy, 5, 188-200. https://doi.org/10.4236/me.2014.53020

MANKIW, G. N. 2000. The inexorable and mysterious trade off between inflation and unemployment. NBER WP. Cambridge. https://doi.org/10.3386/w7884

MARJANOVIC, G.; MAKSIMOVIC, L.; STANISIC, N. 2015. Hysteresis and the NAIRU: The Case of Countries in Transition. Prague Economic Papers, DOI: 10.18267/j.pep.526.

MCADAM, P.; MCMORROW, K. 1999. The NAIRU Concept - Measurement uncertainties, hysteresis and economic policy role. 
MILL, S. J. 1833. „The Currency Juggle“. Taitś Edinburg Magazine (1833). Reprinted in Vol. I of his Dissertations and Discussions. Boston: 1865.

MODIGLIANI, F.; PAPADEMOS, L. 1975. Targets for Monetary Policy in the Coming Year. Brookings Papers on Economic Activity, Brookings Institution: Washington, D.C. https://doi.org/10.2307/2534063

PHELPS, E. S. 1967. Phillips Curves, Expectations of Inflation and Optimal Unemployment Over Time. Economica. https://doi.org/10.2307/2552025

PHILLIPS, A. W. 1958. The relationship between unemployment and the rate of change of money wages in the United Kingdom 1861-1957. Economica. https://doi.org/10.2307/2550759

REITZ, S.; SLOPEK, D. U. 2013. Fixing the Phillips Curve: The Case of Downward Nominal Wage Rigidity in the US. Internal Journal of Finance and Economics. Int. J. Fin. Econ. 19, 122-131 (2014). https://doi.org/10.1002/ijfe.1472

RICHARDSON, P.; BOONE, L.; GIORNO, C.; MEACCI, M.; RAE, D.; TURNER, D. 2000. The concept, policy use and measurement of structural unemployment: estimating a time varying NAIRU across 21 OECD countries. OECD WP, 2000: Economic studies.

RUSTICELLI, E. 2014. Rescuing the Phillips curve Making use of long-term unemployment in the measurement of the NAIRU. OECD Journal: Economic Studies. Vol. 2014/1. https://doi.org/10.1787/eco_studies-2014-5jxrcm2cdff6

SAMUELSON, P. A.; SOLOW, R. M. May 1960. Analytical aspects of Anti-inflation Policy. American Economic Association.

SEKHON, J. S. 1999. Estimation of the Natural Rate of Unemployment: 1955:01-1997: 12. Harvard University, Berkeley.

THORNTON, H. 1802. An Enquiry into the Nature and Effects of the Paper Credit of Great Britain. Edited with an introduction by F. A. von Hayek. New York Rinehart and Company, Inc. 1939.

TINBERGEN, J. 1959. „An Economic Policy for 1936.” Reprinted in his Selected Papers. Edited by L. H. Klaassen, L. M. Koyck, and H. J. Witteveen. Amsterdam: North-Holland Publishing Company.

TINBERGEN, J. 1951. Business Cycles in the United Kingdom 1870-1914. Amsterdam: North-Holland Publishing Company.

TOBIN, J. 1997. Supply Constraints on Employment and Output: NAIRU versus Natural Rate. Cowles Foundation Paper 1150: Yale University, New Haven.

WALLICH, C.H. 1978. Stabilization Goals: Balancing Inflation and Unemployment. The American Economic Review, Vol. 68, No. 2: Papers and Proceedings of the Ninetieth Annual Meeting of the American Economic Association, pp. 159-164.

WATSON, W. M. 2014. What's Natural? Key Macroeconomic Parameters after the Great Recession Inflation Persistence, the NAIRU, and the Great Recession. American Economic Review: Papers \& Proceedings 201, 104(5), 31-364. https://doi.org/10.1257/aer.104.5.31

ZHANG, Ch. 2017. Global Output Gap and Domestic Inflation in China. Panoeconomicus, 2017, Vol. 64, Issue 1, pp. 17-30, UDC 339.9:338.124.4 (510), DOI: 10.2298/PAN150402034Z, 17-30 p. 